His principles of action, and his view of the ambition of physicians for eminence in their profession, are distinctly and happily set forth in a single paragraph of the memoir of his uncle, to which allusion has just been made. He says, "That strife which has for its object the victory of talent, industry and skill, is honorable, and calculated to advance the dignity and interest af the profession; but that man who seeks preëminence by calumny and detraction, rather than by self-exertion, deserves, and should receive, the reprobation of the wise and good."

In his living he was strictly temperate, in his habits extremely neat, and in bis cisplosition cheerful and social. To the qualities of a gentleman, a scholar, and a philanthropist, was added the crowning excellence of a devoted Christian. He was a deacon in the Congregational church, and frequently, in the absence of the pastor, conducted the services of the sanctuary.

\author{
" How beautiful is genius \\ When combined with holiness! How sweet the tones \\ Of carthly harp when touched by Piely's \\ Soft hand, and hung upon Religion's slurine!"
}

In the hearts of a dearly beloved and greatly bereaved family, a large circle of cordial friends, and a grateful, admiring and appreciating community, his memory is enshrined.

\title{
CASE OF ENCEPHALOID DISEASE.
}

[Communicated for the Boston Medical and Surgical Journal.]

THE following is a report of an extraordinary case of encephaloid disease, simulating, in its early stage, sciatica; and terminating fatally within seven months from its first indication.

H. P., merchant; aged 46 years; of healthy parentage ; no case of malignant disease is known to bave prevailed in the family; of lean person, and of nervous temperament; has enjoyed good health, with the exception of neuralgic pains principally affecting the head, but at times erratic. Was seized with all the symptoms of sciatic neuralgia, about the first of last Jume, after having been engaged for a number of hours daily, superintending workmen in the laying out of his grounds, which were then cold and damp. His family physician was called upon to visit him professionally on the 18th of June; who found him complaining of no indisposition, with the exception of lameness, consequent on the pain, which seemed to originate near the sciatic notch, and followed the course of the nerve on the thigh, and its branches around the foreleg.

Having failed to obtain perfect relief, from the usual course of treatment for rheumatism, or neuralyic sciatica, he was recommended to leave his business for a few weeks, and avail himself of the alterative effects of a journey, and the sulphur waters of New York. About the $181 \mathrm{~h}$ of July be reached Saratoga, on his way to Sharon, and immediately after was seized with an aggravated increase of former symptoms; yet no apparent change in the character of the case occurred, until within a few days before leaving for home-having remained in Saratoga 
seven weeks; then a fulness was observed over the ilium, about five inches posterior to the anterior superior spinous process. This swelling was attended by no very decided pain or soreness, even on pressure. In this state he succeeded in reaching home, Sept. 2d, and fiom my notebook I transfer the following record of his condition at that time.

"Pulse 110, and soft; respiration, digestion and urination unimpaired; appetite poor; restless and wakeful, requiring at night from 60 to 100 drops of "McMunn's elixir" to procure any sleep; at times troubled with erratic pains in various parts of the limb, but which are easily relieved by local anodynes, and gentle frictions; sweats immoderately during sleep, but at other times the skin feels natural as regards temperature and moisture. There are no exacerbations of fever, neither has there been, during the whole course of disease, any well-marked general symptoms of acute inflammation.

"Much emaciation exists, generally, but especially on the side affected, from the groin downward. The circumference of the right side of the pelvis is about three inches larger than the opposite. A hard swelling can be felt under the edge of the ilium, of an unyielding hardness, while the swelling over the ilium is softer and elastic to the touch. Posterior, to the distance of six inches from the edge of the ilium, nothing abnormal seems to intervene between the bone and the surface.

"Sept. 25th.- IVishing to determine positively the nature of the case, an exploring needle was inserted to the depth of three inches, in two places, into the posterior swelling. It felt like penetrating new cheese, and nothing escaped but blood slightly sanious, and which did not coagulate. The increase of difference of comparative size, at this time, is six inches.

Subsequent to the above record, the disease steadily progressed, without any amelioration from medicine, except what was obtained from anodynes, until le sunk by exhaustion on the 16th December; all the vital functions being but slightly disturbed until a few days before death.

Post-mortem Examination, 12 hours after death; present Drs. Dickinson, Field and Weston, of this city. Extreme emaciation ; observed the right lower extremity to be five or six inches shorter than the other. After opening the abdomen, by an incision extending from the sternum to pubis, and then by a transverse incision to the usual place of acetabulum, and dissecting back the flap thus formed, an enormous encephaloid tumor was exposed, behind the peritoneum, but pushing that membrane before it until its prelumbar surface occupied the median. line of the body. All the normal tissues, including the lumbar and psoas muscles, were obliterated and absorbed in the great morbid mass. The bones of the pelvis seemed to have undergone the same eremacausis, for nothing remained of the right side of the pelvis, except a portion of the crest of the ilium, the spine of the pelvis, and the tuberosity of the ischium; and these remains were involved with the tumor, and completely honeycombed. The acetabulum having been entirely absorbed, the head of the femur was drawn within the body, and a portion of it, about the size of a half dollar, embracing the insertion of the ligamentum teres, was absorbed and carious. The cœcum was forced to- 
wards the centre of the abdomen; and the right kidney was thrust upward, and occupied a transverse position to the spine. The neck of the bladder was surrounded with the disease; but owing, possibly, to its soft consistence, it had not interfered with the calibre of the urinary passage. Indeed, there was no space within the right side of the pelvis, but what was occupied with the morbid growth, to the dislodgement or destruction of every organ naturally belonging to that cavity.

There were found some adhesions of the surface of the liver, as well as that of the descending colon, to the opposite peritoneal surfaces, which were considered to be of long standing, and the result of some former disease.

The nature of the tumor was decidedly encephaloid; it had the color and consistence of the medullary part of the brain; and when placed on the field of the microscope, it exhibited the angular and caudate cells of that malignant disease. A mass of the disease, sufficient to fill a wash-hand basin, was removed; and, judging from the weight of that, and from what appeared to remain in the body, the whole must have weighed, at least, fifteen pounds.

The causes which seemed to have invested this case, in its early stage, with more than usual obscurity, were-its locality; the absence of every known hereditary taint ; the apparent exemption of the patient from any antecedent symptoms of strumous or carcinomatous disease; and likewise the perfect assimilation of the symptoms of its early stage to those of sciatica. The disease originated, undoubtedly, within the basin of the pelvis, posterior to the peritoneum; in the neighborhood, and involving in some way, either by contiguity or aggregation, the sciatic nerve. Before the tumor was detected by manual examination, beneath the edge of the ilium, it had absorbed a circular portion of that bone, and forced itself through the opening, thus made, pressing upon the inner surfaces of the gluteal muscles, and exhibiting, by its prominence and elasticity, the appearance of an abscess; a deception, which, although suspected, was only entirely removed by exploration.
Bangor, Me., Jan. 8, 1855.
D. McRuer, M.D.

\section{CASE OF EARLY IIVE BIRTH.}

- [Communicated for the Boston Medical and Surgical Journal.]

In the Boston Medical and Surgical Journal for Nov. 15, 1854, there is quoted from the Edinburgh Monthly Journal of Medical Science, the case of a foetus born alive in the fourth month of pregnancy, which lived, or manifested signs of vitality, for nearly an hour. I have recently met with a case scarcely less remarkable, and herewith send it to you.

On the 26th of December last, I was called to attend a woman in labor, who had previously miscarried three times. She was in the sixth month of gestation, having last menstruated on the 5th of August. When the fotus was expelled, pulsation in the cord was strong and regular, and the movements of the child quite lively. The pulsation 